\title{
Bank branch operating efficiency: evaluation with data envelopment analysis
}

\author{
Roozbeh Talebi Zarinkamar $^{\mathrm{a}^{*}}$ and Akbar Alam-Tabriz
}

${ }^{a}$ Department of Management, Ershad Damavand Institute of Higher Education, Tehran, Iran

${ }^{b}$ Department of Management, Shahid Beheshti University, Tehran, Iran

\section{H R O I C L E A B S T R A C T}

Article history:

Received January 20, 2014

Accepted 30 August 2014

Available online

September 92014

$D E A$

Data envelopment analysis

Efficiency

Banking industry

\begin{abstract}
Measuring the relative efficiency of similar units has been a popular research especially when the units were mostly non-financial. Even, similar financial units may not be necessarily evaluated based on traditional financial figures such as return of equities, return of assets, etc. In this paper, we present an empirical investigation to measure the relative efficiency of 30 branches of an Iranian bank named Bank Mellat. The study considers four inputs including operating expenses, interest paid, capital expenditures and fixed assets. In addition, we use customers' bank deposit, commissions and loans paid as output parameters. Using three different data envelopment analyses, the study measures the relative efficiencies of all units. The preliminary results indicate that most banks were working under desirable level of efficiency.
\end{abstract}

(C) 2014 Growing Science Ltd. All rights reserved.

\section{Introduction}

Studying the relative efficiency is one of the concerns in many financial companies such as insurances, banks, etc. (Soltanifar \& Farhadi, 2014) Data envelopment analysis (DEA) has been one of the popular techniques for measuring the relative efficiency of similar units such as bank unites, schools, etc. The advantage of using DEA is that one may easily use the non-financial factors along with the financial numbers to caculate a suitable comparison of different units. DEA has become a popular technique because of simple application and interpretation (Charnes et al., 1978; Banker et al., 1984). During the past three decades, there have been many applications of DEA methods for calculating the relative efficiency of banks (Haslem et al., 1999; Mercan et al., 2003; Fallah et al., 2011). Yang et al. (2010) presented an integrated bank performance assessment and management planning by hybrid minimax reference point - DEA approach. Staub et al. (2010) investigated different factors impacting the relative efficiency of Brazilian banks such as costs and technical efficiencies. They reported that Brazilian banks had severly suffered from low levels of efficiency compared with European or North American banks. They reported that state-owned banks were more cost efficient than other foreign units. Nonetheless, they did not give any indication to claim that the differences in economic efficiency were because of the kind of activity and bank size. 
Avkiran (2010) investigated the relationship between the supper-efficiency estimations and some major key financial ratios for Chinese banking sector. The technique provided some opportunity to determine the inefficient units where there was a low correlation between the supper-efficiency and good financial ratios. Lin et al. (2009) applied various DEA models for 117 branches of a certain bank in Taiwan and reported an overall technical efficiency of 54.8 percent for all banks. They also explained that most branches had been relatively inefficient. Thoraneenitiyan and Avkiran (2009) investigated DEA and stochastic frontier analsysis (SFA) to measure the impact of restructuring and country-specific factors on the efficiency of post-crisis east Asian banking systems. They stated that banking system inefficiencies were primarlity due to country-specific conditions, such as high interest rates, concentrated markets and economic development. DEA was also implemented for banking decisions. For example, Che et al. (2010) applied a combination of Fuzzy analytical hierarchy procedure (AHP) and DEA as a decision making facility for making bank loan decisions.

\section{The proposed study}

The constant return to scale DEA (CCR) was initially proposed by Charnes, et al. $(1978,1994)$ as a mathematical technique for measuring the relative efficiency of decision making units (DMU). One can easily find out how a given DMU works whenever a production function is available.

$\max Z_{0}=\sum_{r=1}^{s} u_{r} y_{r 0}$,

subject to

$\sum_{r=1}^{m} v_{i} x_{i 0}=1$

$\sum_{r=1}^{s} u_{r} y_{r 0}-\sum_{r=1}^{m} v_{i} x_{i 0} \leq 0$

$(r=1, \cdots, s),(i=1, \cdots, m),(j=1, \cdots, n), u_{r}, v_{i} \geq 0$

where $x$ and $y$ represent the input and output vectors, respectively. In addition, $u$ and $v$ are dual variables associated with input/outputs, respectively. The CCR production feasibility set border determines the relative efficiency in which any off-border DMU is considered as inefficient. The CCR model can be detected in two forms of either input or output oriented. The input CCR aims to decrease the maximum input level and can be represented as follows,

$\max Z_{0}=\sum_{r=1}^{s} u_{r} y_{r 0}+W$

subject to

$\sum_{r=1}^{m} v_{i} x_{i 0}=1$

$\sum_{r=1}^{s} u_{r} y_{r 1}-\sum_{i=1}^{m} x_{i j} v_{i}+W \leq 0$

$(r=1, \cdots, s),(i=1, \cdots, m),(j=1, \cdots, n), u_{r}, v_{i} \geq 0$

The difference between Model (1) and Model (2) is associated with the free variable, $W$. When $W>0$ The resturn to scale is in the form in deceasing, when $W=0$ we have a constant return to scale model and finally when $W<0$, the return is to scale in increasing form. Finally, Model (3) demonstrates the maxmin model as follows,

$\max Z_{0}=M$

subject to

$\sum_{r=1}^{m} v_{i} x_{i 0}=1$

$\sum_{r=1}^{s} u_{r} y_{r j}-\sum_{i=1}^{m} x_{i j} v_{i}+d_{j}=0$

$M-d_{j} \geq 0$

$(r=1, \cdots, s),(i=1, \cdots, m),(j=1, \cdots, n), u_{r}, v_{i}, d_{j} \geq 0$ 
where $M$ represents the deviation from the desirable value. One of the issues associated with DEA model is that we may receive more than one efficient unit and to rank the efficient units, Anderson Peterson model can be use.

\section{Case study}

In this paper, we use the proposed model explained in the previous section to measure the relative efficiency of 30 Iranian banks named Bank Mellat located in city of Tehran, Iran. The proposed DEA model of this paper considers 4 inputs including operating expenses, interest paid, capital expenditures and fixed assets. In addition, we use customers' bank deposit, commissions and loans paid as output parameters. Table 1 demonstrates the results of measuring the relative efficiency of 30 units based on the implementation of model 1 and model 2 .

\section{Table 1}

The summary of the results of CCR and BCC models introduced in Model (1) and Model (2)

\begin{tabular}{cccccc}
\hline Unit & CCR & BCC & Unit & CCR & BCC \\
\hline 1 & 0.7576 & 0.8801 & 16 & 1 & 0.5137 \\
2 & 1 & 1 & 17 & 1 & 1 \\
3 & 0.8603 & 1 & 18 & 0.7286 & 0.7301 \\
4 & 1 & 1 & 19 & 1 & 1 \\
5 & 1 & 1 & 20 & 1 & 1 \\
6 & 1 & 1 & 21 & 0.7917 & 1 \\
7 & 1 & 1 & 22 & 0.969 & 1 \\
8 & 0.7627 & 1 & 23 & 1 \\
9 & 1 & 1 & 24 & 1 & 1 \\
10 & 0.5277 & 1 & 25 & 0.6438 & 0.6781 \\
11 & 0.5245 & 0.8653 & 26 & 0.892 & 0.8934 \\
12 & 0.8196 & 1 & 27 & 1 \\
13 & 0.4683 & 1 & 28 & 0.7681 & 1 \\
14 & 1 & 1 & 29 & 1 & 0.7912 \\
15 & 1 & 1 & 30 & & 1 \\
\hline
\end{tabular}

As we can observe from the results of Table 1, most units are represented as efficient ones and the results somewhat confuses decision maker. Therefore, we use Model (3) to measure the efficiency of various units. Table 3 summarizes the results of our survey.

Table 3

The summary of measuring the relative efficiency of 30 units based on minmax model

\begin{tabular}{cccc}
\hline Unit & MinMax model & Unit & MinMax model \\
\hline 1 & 0.6738 & 16 & 0.973 \\
2 & 0.3082 & 17 & 0.2792 \\
3 & 0.5184 & 18 & 0.4779 \\
4 & 0.68 & 19 & 0.4766 \\
5 & 0.9889 & 20 & 0.7707 \\
6 & 0.5144 & 21 & 0.2367 \\
7 & 0.5503 & 22 & 0.3953 \\
8 & 0.526 & 23 & 0.809 \\
9 & 0.4055 & 24 & 0.7032 \\
10 & 0.3008 & 25 & 0.4747 \\
11 & 0.083 & 26 & 0.6389 \\
12 & 0.149 & 27 & 0.4618 \\
13 & 0.2225 & 28 & 0.3166 \\
14 & 0.6217 & 29 & 0.9874 \\
\hline
\end{tabular}

According to the results of Table 3, only one unit, unit 18, is considered to be efficient and the other units are stated as inefficient. The average efficiencies of model 1,2 and 3 are $0.87,0.95$ and 0.53 , 
respectively. In order to have a better insight on the relative efficiency of efficient as well as inefficient units and comparing with the results of maxmin method we apply Anderson Peterson method (Andersen \& Petersen 1993) and Table 4 summarizes the results of our investigation.

\section{Table 4}

The summary of Anderson Peterson method for measuring super efficiency

\begin{tabular}{|c|c|c|c|c|c|c|c|c|}
\hline \multirow[b]{2}{*}{ Unit } & \multicolumn{3}{|c|}{ Efficiency } & \multicolumn{2}{|c|}{ Anderson Peterson } & \multicolumn{3}{|c|}{ Rank } \\
\hline & $\mathrm{CCR}$ & $\mathrm{BCC}$ & MinMax & $\mathrm{CCR}$ & $\mathrm{BCC}$ & $\mathrm{CCR}$ & $\mathrm{BCC}$ & MinMax \\
\hline 1 & 0.7576 & 0.8801 & 0.6738 & - & - & 24 & 25 & 9 \\
\hline 2 & 1 & 1 & 0.3082 & 1.01303 & 1.024 & 16 & 22 & 24 \\
\hline 3 & 0.8603 & 1 & 0.5184 & - & 1.0091 & 19 & 23 & 14 \\
\hline 4 & 1 & 1 & 0.68 & 1.25195 & 1.2519 & 11 & 15 & 8 \\
\hline 5 & 1 & 1 & 0.9889 & 2.09521 & 2.5041 & 4 & 5 & 2 \\
\hline 6 & 1 & 1 & 0.5144 & 2.58889 & 2.5888 & 2 & 2 & 15 \\
\hline 7 & 1 & 1 & 0.5503 & 1.40698 & 1.4069 & 9 & 11 & 12 \\
\hline 8 & 0.7627 & 1 & 0.526 & - & 1.0742 & 23 & 19 & 13 \\
\hline 9 & 1 & 1 & 0.4055 & 1.05127 & 1.0529 & 15 & 21 & 21 \\
\hline 10 & 0.5277 & 1 & 0.3008 & - & 2.5293 & 27 & 4 & 25 \\
\hline 11 & 0.5245 & 0.8653 & 0.083 & - & - & 28 & 26 & 30 \\
\hline 12 & 0.8196 & 1 & 0.149 & - & 1.5724 & 20 & 9 & 29 \\
\hline 13 & 0.4683 & 1 & 0.2225 & - & 1.1036 & 30 & 18 & 28 \\
\hline 14 & 1 & 1 & 0.6217 & 1.05842 & 1.2887 & 14 & 14 & 11 \\
\hline 15 & 1 & 1 & 0.4783 & 1.1323 & 1.4061 & 13 & 12 & 16 \\
\hline 16 & 1 & 1 & 0.973 & 1.4648 & 1.4648 & 8 & 10 & 4 \\
\hline 17 & 0.5137 & 0.6218 & 0.2792 & - & - & 29 & 30 & 26 \\
\hline 18 & 1 & 1 & 1 & 5.5751 & 5.57513 & 1 & 1 & 1 \\
\hline 19 & 0.7286 & 0.7301 & 0.4779 & - & - & 25 & 28 & 17 \\
\hline 20 & 1 & 1 & 0.4766 & 1.33303 & 1.333 & 10 & 13 & 18 \\
\hline 21 & 1 & 1 & 0.7707 & 1.2292 & 1.2292 & 12 & 16 & 6 \\
\hline 22 & 0.7917 & 1 & 0.2367 & - & 1.1377 & 21 & 17 & 27 \\
\hline 23 & 0.969 & 1 & 0.3953 & - & 1.06891 & 17 & 20 & 22 \\
\hline 24 & 1 & 1 & 0.809 & 1.59994 & 1.5999 & 6 & 8 & 5 \\
\hline 25 & 1 & 1 & 0.7032 & 1.6411 & 1.641 & 5 & 7 & 7 \\
\hline 26 & 0.6438 & 0.6781 & 0.4747 & - & - & 26 & 29 & 19 \\
\hline 27 & 0.892 & 0.8934 & 0.6389 & - & - & 18 & 24 & 10 \\
\hline 28 & 1 & 1 & 0.4618 & 1.57122 & 2.5712 & 7 & 3 & 20 \\
\hline 29 & 0.7681 & 0.7912 & 0.3166 & - & - & 22 & 27 & 23 \\
\hline 30 & 1 & 1 & 0.9874 & 2.35804 & 2.358 & 2 & 6 & 3 \\
\hline
\end{tabular}

As we can observe from the results of Table 4, Anderson Peterson method (Andersen \& Petersen, 1993; Anderson et al., 2011) yields the same results as the maxmin method.

\section{Discussion and Conclusion}

In this paper, we have presented an empirical investigation to study the performance of selected banks in city of Tehran, Iran. The proposed study has considered 4 inputs including operating expenses, interest paid, capital expenditures and fixed assets. In addition, the study has used customers' bank deposit, commissions and loans paid as output parameters. Using different DEA techniques, the study has measured the relative efficiency of various 30 branches. The results have indicated that most banks were operating well above the average. In addition, the implementation of minmax method has appeared to present better results in terms of super efficiency. The results of implementation of DEA techniques have been repeatedly used in other applications. Ehsani and Danaei (2014) applied a combination of DEA and Technique for Order of Preference by Similarity to Ideal Solution (TOPSIS) for ranking banks. In their survey, they first used CCR method to rank all different banks and then used TOPSIS technique to rank efficieny units. Shabani and Shams (2014) measured the performance of accepted investment companies in Tehran's stock exchange by value efficiency analysis, which is an extension of data envelopment analysis. Rahimian and Soltanifar 
(2013) presented an application of DEA based Malmquist productivity index in university performance analysis.

\section{Acknowledgement}

The authors would like to thank the anonymous referees for constructive comments on earlier version of this paper.

\section{References}

Andersen, P., \& Petersen, N. C. (1993). A procedure for ranking efficient units in data envelopment analysis. Management science, 39(10), 1261-1264.

Anderson, D., Sweeney, D., Williams, T., Camm, J., \& Martin, R. (2011). An Introduction to Management Science: Quantitative Approaches to Decision Making, Revised. Cengage Learning.

Avkiran, N. K. (2010). Association of DEA super-efficiency estimates with financial ratios: Investingating the case for Chinese banks. Omega, 39(3), 323-334.

Banker, R. D., Charnes, A., \& Cooper, W. W. (1984). Some models for estimating technical and scale inefficiencies in data envelopment analysis. Management Science, 30(9), 1078-1092.

Charnes A, Cooper, W. W., \& Rhodes, E. (1978). Measuring the efficiency of decision making units. European Journal of the Operational Research, 2, 429-44.

Charnes A, Cooper W. W., Lewin, A., \& Seiford, L. M. (1994). Data envelopment analysis: theory, methodology and applications. Massachusetts: Kluwer Academic Publishers.

Che, Z. H., Wang, H. S., \& Chuang, Ch-L. (2010). A fuzzy AHP and DEA approach for making bank loan decisions for small and medium enterprises in Taiwan, Expert Systems with Applications, 37(10), 7189-7199.

Ehsani, M., \& Danaei, A. (2014). A DEA-TOPSIS approach for ranking credit institutions. Management Science Letters, 4(9), 2071-2076.

Fallah, M. Aryanezhad, M.B., Najafi, S.E., \& Shahsavaripour, N. (2011). An empirical study on measuring the relative efficiency using DEA method: A case study of bank industry. Management Science Letters, 1(1), 49-56.

Fu, X. M., \& Heffernan, S. (2007). Cost X-efficiency in China's banking sector. China Economic Review, 18(1), 35-53.

Haslem, J. A., Scheraga, C. A., \& Bedingfield, J. P. (1999). DEA efficiency profiles of U.S. banks operating internationally. International Review of Economics \& Finance, 8(2), 165-182.

Hwang, C. L., \& Yoon, K. (1981). Multiple Attribute Decision Making Methods and Applications. Springer, Berlin Heidelberg.

Lin, T. T., Lee, Ch-Ch., \& Chiu, T-F. (2009). Application of DEA in analyzing a bank's operating performance. Expert Systems with Applications, 36(5), 8883-8891.

Mercan, M., Reisman, A., Yolalan, R., \& Burak Emel, A. (2003). The effect of scale and mode of ownership on the financial performance of the Turkish banking sector: results of a DEA-based analysis, Socio-Economic Planning Sciences, 37(3), 185-202.

Mester, L. J. (1996). A study of bank efficiency taking into account risk-preferences. Journal of Banking \& Finance, 20(6), 1025-1045.

Rahimian, M \& Soltanifar, M. (2013). An application of DEA based Malmquist productivity index in university performance analysis. Management Science Letters , 3(1), 337-344.

Shabani, M \& Shams, N. (2014). Measuring the performance of accepted investment companies in Tehran's stock exchange by value efficiency analysis. Management Science Letters , 4(6), 12291232.

Soltanifar, M \& Farhadi, F. (2014). An application of data envelopment analysis for measuring the relative efficiency in banking industry. Management Science Letters, 4(5), 1021-1026.

Srairi, S. A. (2010). Cost and profit efficiency of conventional and Islamic banks in GCC countries. Journal of Productivity Analysis, 34(1), 45-62. 
Staub, R. B., Da Silva e Souza, G. \& Tabak, B. M. (2010). Evolution of bank efficiency in Brazil: A DEA approach. European Journal of Operational Research, 202(1), 204-213.

Thoraneenitiyan, N., \& Avkiran, N. K. (2009). Measuring the impact of restructuring and countryspecific factors on the efficiency of post-crisis East Asian banking systems: Integrating DEA with SFA. Socio-Economic Planning Sciences, 43(4), 240-252.

Yang, J.B., Wong, B.Y.H., Xu, D.L., Liu, X.B. \& Steuer, R.E. (2010). Integrated bank performance assessment and management planning using hybrid minimax reference point - DEA approach. European Journal of Operational Research, 207(3), 1506-1518. 